\title{
How to communicate effectively in graduate advising
}

\author{
H.H. Wagner ${ }^{a \star}$, S. Temple ${ }^{\text {b }}$, I. Dankert ${ }^{c}$, and R. Napper ${ }^{d}$ \\ a Department of Ecology and Evolutionary Biology, University of Toronto, Mississauga, ON L5L 1C6, \\ Canada; ${ }^{\mathrm{b}}$ The Fluent Self Company, St Austell, Cornwall PL26 7AY, UK; ${ }^{\mathrm{c}}$ Faculty of Business \\ Management and Social Sciences, Osnabrück University of Applied Sciences, 49076 Osnabrück, \\ Germany; ${ }^{\mathrm{d}}$ TA Works, Oxford, OX4 1YL, UK \\ *helene.wagner@utoronto.ca
}

\begin{abstract}
This paper completes a two-part series on graduate advising that integrates concepts from adult learning, leadership, and psychology into a conceptual framework for graduate advising. The companion paper discussed how to establish a learning-centered working relationship where advisor and graduate student collaborate in different roles to develop the student's competence and confidence in all aspects of becoming a scientist. To put these ideas into practice, an advisor and a student need to communicate effectively. Here, we focus on the dynamics of day-to-day interactions and discuss (1) how to provide feedback that builds students' competence and confidence, (2) how to choose the way we communicate and avoid a mismatch between verbal and nonverbal communication, and (3) how to prevent and resolve conflict. Miscommunication may happen out of a lack of understanding of the psychological aspects of human interactions. Therefore, we draw on concepts from Educational Transactional Analysis to provide advisors and students with an understanding of the psychological aspects of graduate advising as a basis for effective communication. Case studies illustrate the relevance of the concepts presented, and four worksheets (Supplementary Material) support their practical implementation.
\end{abstract}

Citation: Wagner HH, Temple S, Dankert I, and Napper R. 2016. How to communicate effectively in graduate advising. FACETS I: 280-299. doi: 10.1 1 39/facets-2015-0014

Editor: Marie-Claire Shanahan

Received: December 21, 2015

Accepted: August 24, 2016

Published: December 21, 2016

Note: This is a companion paper to facets-2015-00 I3

Copyright: (C) 2016 Wagner et al. This work is licensed under a Creative Commons Attribution 4.0 International License (CC BY 4.0), which permits unrestricted use, distribution, and reproduction in any medium, provided the original author(s) and source are credited.

Published by: Canadian Science Publishing

\section{Introduction}

Human factors, and specifically the emotional competencies of advisors and graduate students that are displayed in day-to-day interactions, may be a main contributor to program completion, yet the emotional aspect of graduate advising is understudied (O'Meara et al. 2013). This discrepancy may be rooted in an academic culture of separating intellect and emotion, or related to common beliefs that emotional competence either can't be learned or that it is difficult to learn (O'Meara et al. 2013). We propose that to be effective, communication must account for the emotional experiences of advisors (Amundsen and McAlpine 2011) and graduate students (Jazvac-Martek et al. 2011).

This paper provides a brief overview of the underlying psychological processes that are likely to affect the dynamics of the working relationship between advisors and graduate students. Many models from different disciplines and schools of thought aim to explain human interactions, and a systematic overview is beyond the scope of this paper. The pragmatic goal here is to provide a collection of concepts that integrate with the conceptual framework presented in the companion paper and enable advisors 
and students to reflect on and enhance their interactions by increasing their emotional literacy (Goleman 1996; Steiner 2003) and communication skills.

We will draw largely on Transactional Analysis (Berne 1961; 1964) and its offspring, such as the Functional Fluency Model (Temple 2004) or Empowerment Dynamics (Emerald 2009). Transactional Analysis is a theory of inter-personal communication, development, growth, and change that reflects a philosophy of mutual- and self-respect and acceptance and is based on a belief in everyone's capability to learn and their potential for change. It has important applications in education (Napper and Newton 2014; Barrow and Newton 2016), organizations (Hay 2009), counseling and psychotherapy, and is used worldwide in managerial leadership training. Key to its success is a consistent framework of concepts that are easy to understand and that can be directly applied to increase personal and professional effectiveness.

\section{Conceptual framework}

While a systematic overview of the theoretical body of Transactional Analysis and the links between its concepts is beyond the scope of this paper, many Transactional Analysis concepts are linked by the notion of OK-ness, which describes, for any given moment, our attitude toward ourselves and toward others. The concepts presented here to help improve communication in graduate advising can also be linked to concepts from adult learning, leadership, and doctoral education discussed in the companion paper.

The companion paper presented a collaborative learning model, based on Situational Leadership II ${ }^{\circledR}$ (Blanchard et al. 1985), where advisors support students' development of competence and confidence in the range of skills related to becoming a scientist. The Functional Fluency model (Temple 2004, 2015) matches well with Situational Leadership II ${ }^{\circledR}$ : where the leadership model helps in analyzing the situation to identify what type of supervisory intervention is called for, Functional Fluency provides options for implementing the intervention through communication.

For each new type of task, students cycle through four development levels ("Enthusiastic Beginner", "Discouraged Learner", "Cautious Performer", and "Self-reliant Achiever"; Blanchard et al. 1985), and their needs regarding feedback will likely change along the way. Progress through the Discouraged Learner stage may require students to overcome internal resistance to change their perspective on the world (Transformative Learning; Stevens-Long et al. 2012; see companion paper). At this point, it can be helpful to identify possible ways in which students may be discounting the actual problem that they are experiencing: students may fail to recognize either the existence of a problem, its personal significance, its solvability, or their personal capacity to contribute to a solution. The concept of "Discounting" (Mellor and Schiff 1975; Macefield and Mellor 2006) stresses the importance of identifying and overcoming such discounts by recognizing and accepting what is, and why it matters, before considering solutions and one's personal ability to take appropriate action.

Conflicts in graduate advising often share a common pattern of counter-productive interactions that can be described by the Drama Triangle (Karpman 1969, 2014), where the student and the advisor dynamically move between the roles of Victim, Persecutor, and Rescuer. In contrast, the Empowerment Dynamics model (Emerald 2009) provides a positive vision of the dynamics and interactions in an effective working relationship, where the student and the advisor collaborate in the roles of Creator, Challenger, and Coach. The contrast between "Victim orientation" and "Creator orientation" in this model relates to student agency, i.e., the extent to which students feel they have the power to enact change and shape their own lives in a specific context (O'Meara et al. 2013). The focus of the Empowerment Dynamics model on desired outcomes and constructive collaboration promotes the 
development of negotiated agency (Jazvac-Martek et al. 2011), where students develop their own intentions and negotiate how to pursue them.

\section{Provide feedback that builds competence and confidence}

Feedback plays a central role in training graduate students to become independent scientists who hold themselves to the highest standards. As students learn the many skills related to being a scientist, they will need varying types of feedback and support, depending on whether they are in the Enthusiastic Beginner, Discouraged Learner, Cautious Performer, or Self-reliant Achiever stage with respect to the current task (see companion paper). Also, many students today want frequent, personal, focused, positive feedback from their advisors (Mohr et al. 2011). Students who grew up with constant praise may require frequent encouragement to keep motivated (Eckleberry-Hunt and Tucciarone 2011) and may at the same time have problems identifying their achievements. This section discusses (1) how to provide feedback that builds competence and confidence; (2) how to help students develop reflective learning skills, depending on their learning stage with respect to the task at hand; and (3) how to use the power of positive recognition to keep students motivated. Worksheet D (Supplementary Material) provides three templates for processing learning experiences at different stages of learning, and the approach is illustrated by Case Study 1 (Box 1).

Box 1. Case study 1.

This case study continues an example introduced in the companion paper. Gray is a student who has been struggling with the transition from undergraduate education to graduate research training and Dr. Beta is his advisor.

Beta recently read that millenial generation students may be used to constant praise, and she asks Gray whether this seems true based on his experience. Gray confirms and relates how, as an undergraduate student, he once dropped a course because the professor did not seem to be impressed with him. This was a new experience for Gray, who did not know at the time how to handle it.

Beta reflects that her own experience growing up and through graduate school had been very different: most of the time, no news was good news. Her graduate advisor would let her work away without interfering unless there was a problem. Beta wonders aloud how Gray is coping with graduate school where there isn't a culture of constant praise or instant feedback in terms of grades. Beta certainly has not been giving Gray that much positive reinforcement, although it may often have been implied.

Gray opens up: he is still struggling with the transition and would have quit early on had he not realized that many fellow students are having similar experiences. Gray really needs to hear from Beta that he is doing well. The lack of praise is eating away his confidence, even though Gray is convinced that the project is important and that he can do it. After all, he has always been good at school. But now, sometimes Gray thinks that he is not good at anything and then finds it hard to focus.

After a pause, Beta acknowledges that maybe it is time for both of them to learn. It is not easy for her to give praise when she also sees what needs to be improved. However, Beta has just realized that she will need to find a way to balance criticism with positive comments to avoid undermining the student's confidence-as long as she can be sure that Gray will take the criticism to heart and won't selectively hear only the positive messages. 
Box 1. (concluded)

Gray is perplexed: of course he takes the criticism to heart! However, when he just feels inadequate, he loses the courage to address specific problems, especially if he doesn't know how to address them. Beta asks for a concrete example. Gray refers to a recent committee meeting, where all three committee members just pointed out all the things that were wrong with his plans for his second experiment, without suggesting solutions, and very little time was spent on his report of the ongoing first experiment that he had successfully started.

Beta apologizes for the imbalance. She suggests that they sit down together now and reflect on the experience with the first experiment. At their next meeting, they would then discuss how Gray could address the problems with the second experiment. Gray agrees and thanks Beta for the suggestion. They use the column for "Cautious Performer" in Worksheet D (Supplementary Material) to go over the experience of the first experiment. Beta thus lets Gray identify both the positives and negatives, and the advisor makes an effort to offer praise and express appreciation for what the student has done well. Beta can sense the tension dissipating and is relieved to see that, with some gentle guidance, Gray is also able to recognize the limitations of his work.

At their next meeting, the advisor and the student agree to reflect on the experience with the criticism of the second experiment from a Discouraged Learner's perspective. Beta checks whether the student is ready to look at this together and Gray confirms. Beta lets Gray recount his experience during the committee meeting and asks how he had felt. Gray slowly explains: he had felt very discouraged and had felt trapped because he did not see a way forward. After the meeting, Gray was sad and angry at the same time and could not focus on the work for several days. Beta nods and kindly comments that this is not a comfortable place to be in. Gray briefly smiles: no, it isn't. He feels better now.

Beta asks what options Gray had contemplated. The student admits having considered giving up graduate school, or looking for a new advisor. Could he see any other options? Yes, he could change the research question again, but he had already tried that several times without success. How about confronting the advisor directly? Gray shudders: he would not have dared to do so had Beta not opened the conversation last week. How about working through the problem with the design of the experiment? Well yes, but how? Nothing seems to work.

Now Beta smiles: "Well, I may be challenged in giving praise, but I'm good at problem solving. Maybe I could teach you how to work through an open-ended problem?" Gray quickly responds:

"Yes please! I would really appreciate it. I have never learned how to do this".

\section{How feedback affects students}

Incoming graduate students may be used to receiving feedback on their written work passively, without requirements for following up and improving their work (Boud and Molloy 2013). Indeed, graduate research supervision is one of the few situations in higher education where multiple loops of feedback comments and revision are the norm, which reflects that learning to critically evaluate and improve one's own work is a central skill in becoming a scientist. For feedback to be effective, the student needs to (1) know the relevant standards, (2) compare those standards to their own work, and (3) take action to close the gap between the two (Sadler 1989). The advisor's task is not only to provide comments on the student's work but also to ensure that the student follows up on them and to monitor the effect; the advisor thus learns from the response and, if necessary, adapts the way feedback is provided (Boud and Molloy 2013). 
Students may need guidance to become active learners who take responsibility for understanding what is required of them and whether their work meets the expectations within their scientific field (Boud and Molloy 2013). Once students understand the standards of the discipline and the reasons why they should adhere to them, they are likely to agree that it is much better to get constructively critical comments early on than to get them later, for example at their defense, when it may be too late to address them. As graduate advisors, we are also role models in how to invite and learn from feedback.

Feedback is a process that involves both positive and negative emotions (Molloy et al. 2012). Feedback, along with other forms of recognition, comes in five flavors (Napper and Newton 2014; Temple 2016), as illustrated in Fig. 1: (1) Unconditional positive feedback, or acceptance; (2) conditional positive feedback, or approval; (3) conditional negative feedback, or disapproval; (4) unconditional negative feedback, or rejection; and (5) no feedback, or discount. Indeed, graduate advisors may think that if they say nothing, it indicates that all is well and that the student is on the right track. However, a student may feel ignored, slighted, or rejected by a lack of communication and may interpret it as not being considered worthy of the advisor's attention.

There is a direct link between feedback types and the goal of developing the student's competence and confidence in doing research (see companion paper): confidence does not result from competence alone but from the combination of competence and self-esteem. Conditional feedback, which is specific to the student's work, helps build competence, whereas unconditional feedback either builds (positive) or undermines (negative) self-esteem (Napper and Newton 2014; Fig. 1).

Advisors spend a lot of time and energy on providing feedback, for example on draft versions of presentations, reports, and manuscripts. The majority of this feedback is often negative conditional: marking up text for improvement, though meant constructively, signals to students that their work was not good enough. Sometimes students will take conditional negative feedback personally and feel rejected ("I'm inadequate"), which undermines their self-esteem. This can be avoided by framing critical remarks as positive suggestions: focus on what is wanted rather than what is not wanted. For instance, one might say "You can help readers follow your argument by breaking up this long and complex sentence into several short sentences", rather than saying "This sentence is much too long". This positive way is most likely to be effective and can be further enhanced by topping it up with some authentic positive, conditional or unconditional recognition.

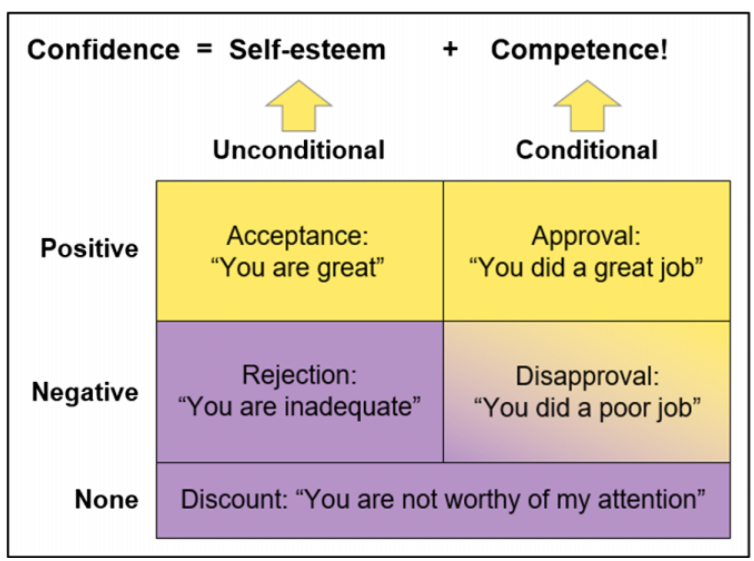

Fig. 1. Contribution of different feedback types to confidence building. Acceptance and approval are effective types (gold color) and rejection and discount ineffective types (purple color), whereas disapproval may contribute to competence building if it is sufficiently balanced with positive feedback. Adapted from Napper and Newton (2014) and Temple (2016). 
It is important to balance conditional negative feedback by authentic positive, conditional or unconditional feedback, or it may come across as destructive and fault-finding. The "feedback sandwich" (Docheff 1990) provides an easy-to-remember formula: start with something positive (bread), provide conditional negative feedback (nutritious filling), end with something positive (more bread), and adapt the ratio of bread to filling to the student's present ability to digest criticism. It is important to keep the positive feedback authentic and personalized to the individual (Napper and Newton 2014): students may sense rather accurately whether the positive comments are authentic or just a formula. This is communicated largely through nonverbal communication.

Some details in wording can make a big difference in helping students learn from feedback. For instance, the word "but" implies criticism, and it effectively negates what was said before. We can turn the connotation from criticism to praise by replacing "but" with "and" (Hyland and Hyland 2001). Another strategy is to make positive conditional feedback personal and negative conditional feedback impersonal. Instead of saying "The manuscript is much improved, but you need to work on your grammar and style", it is better to say "You did a great job on this revision, I like how you developed the story line. [Pause]. I think the next step would be to review grammar and style. [Specific comments]". The last sentence applied two additional strategies (Hyland and Hyland 2001): turning the criticism into a suggestion, and phrasing it as a personal view instead of a fact.

\section{Promote significant learning}

Students who are new to a field or task (Enthusiastic Beginners; see companion paper) have yet to learn things that are likely are second nature to their advisor. This includes making connections between textbook knowledge and the specific context of a research project, learning about disciplinary standards, learning how to do things and why they are done in a specific way, or learning how to solve open-ended problems and develop new skills independently. Students who are new to a task often over-estimate their own skill level (Kruger and Dunning 1999), which may indicate that they do not fully understand what is expected.

Each graduate student's learning journey is different, and what may seem self-evident to the expert may be a significant piece of learning for the novice. Enthusiastic Beginners may be encouraged to keep a log of their significant learning experiences, reflecting on their personal "aha" moments: it does not matter how big or small they are, the only criterion is that they are meaningful for the student. To ensure that the experience is fully processed, Worksheet D (Supplementary Material) provides a template that follows the sequence of Kolb's experiential learning model (Kolb 2014): Experience, Reflection, Analysis, and Action Plan. In our experience, inviting students to periodically share a synthesis of their reflections can help the advisor to better understand each student's individual learning journey, celebrate their initial achievements, ensure that significant learning is occurring and appropriately processed, and gauge when a student is ready for more information.

\section{Help overcome roadblocks}

Worksheet D (Supplementary Material) provides a template for supporting a student who is stuck in the Discouraged Learner stage. When a learner gets stuck, this is often related to a discount of a problem at one of four levels (Mellor and Schiff 1975; Macefield and Mellor 2006) that match the four elements of the experiential learning cycle (Napper and Newton 2014): the existence of a problem (Experience), its personal significance (Reflection), its solvability (Analysis), or the personal capacity to solve the problem (Action Plan). To overcome the obstacle, it is useful to work through the four levels sequentially: before the existence of a problem and its personal significance are acknowledged, discussions about possible solutions and one's personal capacity to act on them tend to be fruitless. 
We have often observed that students in the Discouraged Learner stage will blame themselves for their apparent failure to overcome a challenge; they may feel ashamed and literally vanish. The key is for them to realize that their emotional experience is part of the process of learning, and it is not "just them" (see companion paper). Once they have identified the real problem and understood how it is affecting them, they will often manage to come up with possible solutions for a way forward.

The key challenge for the advisor is to let students work through the problem themselves and not provide suggestions or answers. The first step is to create the conditions where the student can open up about their emotional experience; for example by sharing the learning model or by stating simple observations of the student's behavior in encouraging nonjudgmental ways, as illustrated in Case Study 1 (Box 1). Then, the advisor listens patiently and asks open questions as required (active listening; Johnson 2014). Before moving to solutions, the advisor ascertains that the student has named what is really going on for them, what the root problem is, why it is important, and how it is affecting the student personally. Then, the advisor invites the student to list several possible solutions, after which the advisor may add some more from their own experience or imagination-it does not matter whether these are feasible or not, the point is to show that there are alternative options. Finally, the student chooses which way to go, and the advisor helps break it down into small manageable steps. The advisor asks the student to identify the next small step and commit to it and to a deadline, then follows up on it and offers authentic praise and appreciation when the student has completed it.

We can only invite students to open up about their challenges; we cannot require them to do so. If a Discouraged Learner seems uneasy to discuss an issue with their main advisor, the advisor may suggest that the student speak with another person, such as a committee member or graduate coordinator. Finally, a student experiencing a crisis situation may need to be referred to professional counseling services.

\section{Build trust in own skills}

Once graduate students have developed the necessary skills to perform a task, the next step is for them to develop the confidence that they can do the task independently and trust their own judgment (Cautious Performers). Doing the thinking for them, by providing detailed, specific feedback on their work, for example, is counter-productive at this stage. The advisor can help students develop their own judgment by asking learning questions that invite students to state their own thoughts (Worksheet D in the Supplementary Material). The advisor thus refrains from commenting on a student's work but may comment on the student's own evaluation.

\section{Keep students motivated}

While Self-reliant Achievers require little supervision, they do need to feel appreciated for their work (Blanchard et al. 1985). Inviting them to identify their strengths and successful strategies can help build confidence and turn previous learning experiences into important resources for future learning (Jackson and McKergow 2007; Kluger and Nir 2009).

Positive recognition, such as praise or appreciation, is a powerful motivator that is surprisingly undervalued. This is true for learners at all stages, and indeed, we have observed that students are often shocked to learn that their advisors are also human beings who have a need for recognition. There is an important distinction between praise (e.g., "Well done!") and appreciation (e.g., "You have stated your objectives very clearly"). Praise implies judgment and is often unspecific, so that it provides little useful information for repeating what was done well and for generalizing to other situations. Appreciation expresses a positive awareness about an aspect of a person or of what someone has done (Kline 2009). Personal, specific, truthful, and sincere appreciation helps students to recognize and 
Table 1. Common cultural norms about recognition and how to overcome them. Adapted from Steiner (2003).

\section{Cultural norms-the set of rules}

Don't give positive recognition to others; they might be embarrassed or suspicious of you.

Don't ask for positive recognition; if you have to ask, it's not the real thing.

Don't accept positive recognition from others; you don't know what you might be letting yourself in for.

Don't refuse negative recognition from others; you probably deserve it.

Don't give yourself positive recognition; that's showing off and is unacceptable.
Permissions to make a new set of "rules" and learn to behave differently

It's OK to give positive recognition to others-you can ask them first if that seems a good idea.

It's OK to ask for positive recognition from others-they would probably love the opportunity.

It's OK to accept positive recognition from others when it feels good to let it in.

It's OK to refuse negative recognition from others, especially when it doesn't feel helpful or kind.

It's OK to give yourself positive recognition; if necessary you can do so when others aren't around.

own their specific achievements. This can support students in becoming less dependent on recognition from others (Case Study 1). One participant of a graduate student workshop, once aware of the issue, decided deliberately to wean themself off the need for constant praise to adapt to the professional world within and beyond academia.

Why would we rather say nothing than offer praise or appreciation if positive recognition is so useful? We are taught to follow rules in how we give and receive recognition (Table 1) that are passed on as cultural norms (Steiner 1971, 2003). For instance, we may hesitate to give praise to peers or superiors to avoid "putting ourselves above them". Other cultures may have different norms, often involving the requirement for "saving face" in relationships and showing respect for authority (Dimitrov 2009). Becoming aware of cultural norms and their potential negative impact is the first step to changing our behavior and becoming more effective through offering and accepting sincere appreciation.

\section{Choose how you communicate}

How often do we experience a discrepancy between our good intentions and undesired outcomes when interacting with others? It is important to recognize that communication has an explicit, verbal component, and an implicit, nonverbal component. Effective communication requires congruence between the two, so that we say what we mean and mean what we say (Temple 2016). This section (1) highlights the importance of our attitudes toward ourselves and toward others for authentic and congruent communication, and (2) explains how to choose effective ways of communicating flexibly depending on the situation. Case Study 2 (Box 2) illustrates the concepts, and advisors or students can use Worksheet E (Supplementary Material) individually to reflect on their own attitudes and behaviors and to evaluate alternatives.

\section{Maintain a constructive attitude}

In our experience, "people are not their behaviors" is a useful presupposition for effective communication. Sometimes, when we become thoroughly frustrated with each other, this notion is hard to accept for advisors and for graduate students alike. Labeling people, or challenging the person instead of challenging their behavior, leads to ineffective communication. If we accept that humans have the fundamental ability to learn, then it follows that people cannot be defined by their behaviors, because transformative learning (Mezirow 1997; see companion paper) will affect behavior. Also, how we make sense of a situation has a lot to do with our prior experiences, and an advisor and a student may experience and interpret the same situation very differently. 
Box 2. Case study 2.

Like many graduate advisors, Dr. Gamma is full of ideas and often suggests to graduate students how they could do some new analyses or write their paper differently to take their work to a higher level. This would ultimately benefit the students as their work may get published in highly ranked scientific journals. In the short run, however, this typically means more work for them, and they may need to acquire new skills to follow through on the advisor's recommendations.

Over time, Gamma has noticed that different students tend to respond differently: Red would first confront him and question why she has to do this; then once she saw the advantage, she would jump right in and do it. With Green, it really depends on whether she thinks she can do what is required. If yes, Green will go along and do a good job, if not, she seems to shut down; somehow "the light goes off" and she becomes passive. Blue on the other hand would not voice any concerns about the work but quietly add it to her ever-growing to-do list and work even more. As different as these responses are, considering them jointly, using Accounting mode, helped Gamma realize that his job is not only to make great suggestions, but to help each student "get on board".

Red's behavior fits a Fight response (Fig. 1), Green tends to respond with Freeze, and Blue with Flee. The commonality is that the advisor's well-intended suggestions may throw them out of Flow, and this needs to be addressed before they can get on with the new task.

When Red is in a confrontational Fight position, the student is likely to perceive Gamma's behavior not as Structuring but as Dominating (Fig. 2). Red might respond best initially to Cooperative or Spontaneous mode behaviors, as these put the student on the same level as the advisor. In fact, a good strategy may be for Gamma to tell Red about the exciting new idea and ask her for an opinion, then outline (or develop with her) alternative options, including the status quo, evaluate them together, and let the student decide which way to go. If Red can see the advantage, she is likely to go for it, and it really makes a difference if she is consulted, taken seriously, and can take the decision.

Green and Blue have in common that they tend to lose confidence (Discouraged Learner). This calls for a combination of Nurturing and Structuring. Gamma may use active listening to help them voice their concerns about lack of skills or overwhelming workload. They have yet to learn that these are valid concerns that can be voiced and addressed, rather than discounted. The advisor could use the template for helping Discouraged Learners overcome a roadblock (Worksheet D in the Supplementary Material): let the student name the problem and acknowledge how it is affecting them. Then, and only then, ask the student to list possible solutions (Structuring), to which Gamma may add a few more. At this point, using humor and suggesting a couple of unrealistic solutions (Spontaneous) can break the ice and help students gain confidence in their ability to come up with better solutions than these. Once a student has decided which way to go and has identified the next small step to take, Gamma might ask how he could best support them (Cooperative). This helps students build confidence, as they feel supported while taking responsibility for their own learning.

On a basic level, the perspective on the world-i.e., the set of assumptions through which we understand our experiences and which shape and limit our expectations, perceptions, thoughts, and feelings (Mezirow 1997) — can be characterized by four life positions (Berne 1962) as described in Fig. 1. Clearly, we will experience the same situation differently from each of these different positions. 
Consider how you might respond if a graduate student bursts into tears. Figure 1 illustrates the four positions you could take, based on your attitudes toward yourself and toward the student (Ernst 1971; Napper and Newton 2014): do you consider the student to be capable ("You're OK") or not capable ("You're not OK") of working through whatever caused their emotional upset? Do you consider yourself to be capable ("I'm OK") or not capable ("I'm not OK") of responding to the situation and supporting the student in working through it? In such a situation, it is crucial to consciously move to an "I'm OK, you're OK" position and assume that both are fundamentally capable of dealing with the situation and addressing the underlying issue-if not right now then at the next meeting.

The four positions have different emotional qualities and tend to result in different behaviors that are related to the basic ways by which humans respond to a perceived threat (Ernst 1971; Fig. 2). Unlike "Fight" ("I'm OK, you're not OK"), "Flee" ("I'm not OK, you're OK), and "Freeze" ("I'm not OK, you're not OK"), only "Flow"-type behavior ("I'm OK, you're OK") is productive. Staying in any of the other positions may eventually lead to problems, such as open conflict, drop-out, or mental health issues.

While we may have a tendency to take one of the positions more often than others, we are likely to move between them more often than we realize, even during the course of a conversation. Switches between Fight and Flee are common (e.g., passive-aggressive behavior), and expecting to be in Flow all the time would be unrealistic. Indeed, each position has its use in situations where the relationship has become unhealthy (Heiller and Sills 2010). Recognizing which of the four positions we are in at any specific moment may thus provide useful information about what is going on and provide a clue for how to get back into a constructive Flow position (Worksheet E in the Supplementary Material):

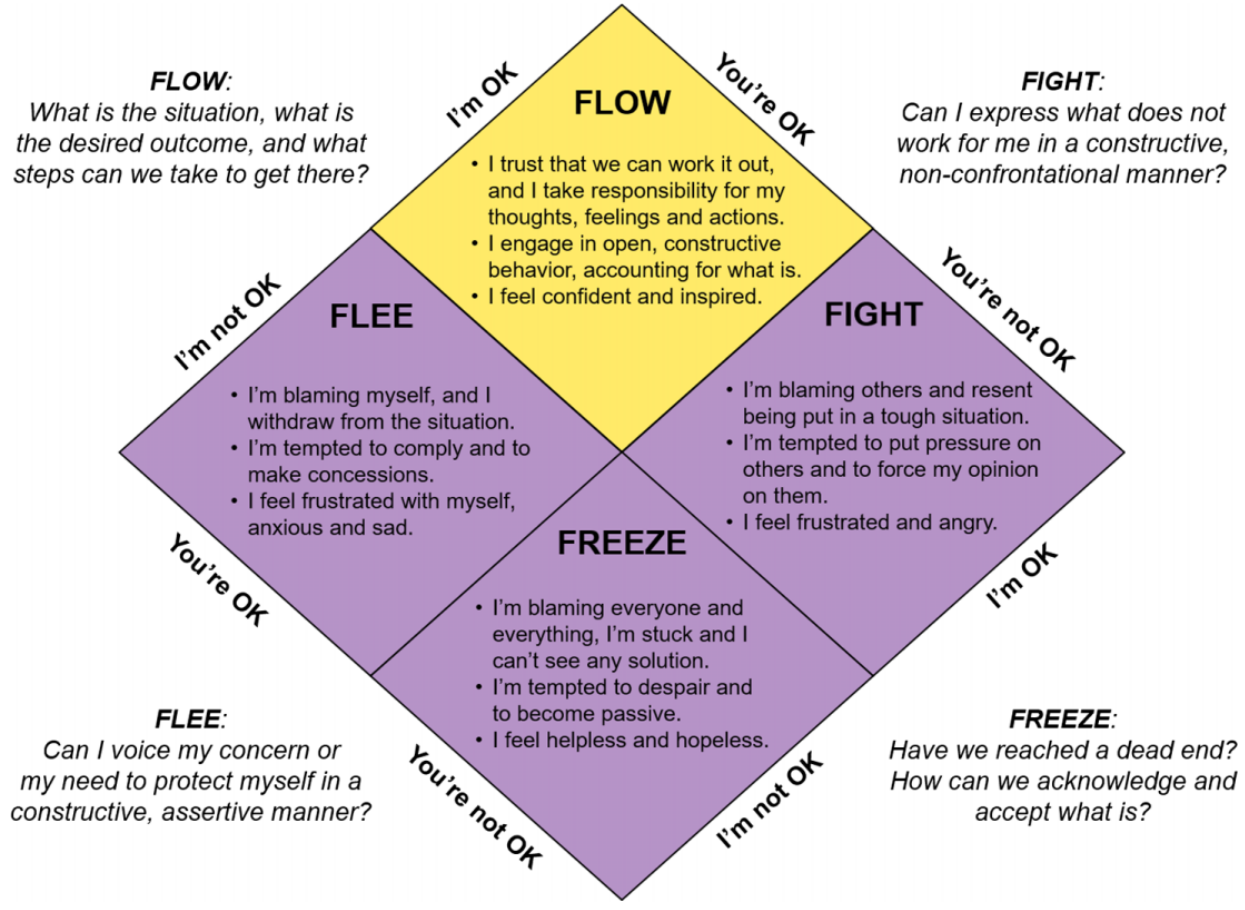

Fig. 2. The four "life positions" and related patterns of behavior. The only constructive position (gold color) is Flow or "I'm OK, you're OK". The chart characterizes the perspective on the world of an individual at a specific moment. It applies separately to the advisor and to the student, whose positions may or may not match. Adapted from Ernst (1971) and Temple (2016). 
(1) When I'm finding myself in Fight, this may indicate that something does not work for me and I perceive the need to establish a boundary. Can I name it and voice it in a constructive, nonconfrontational manner? (2) When I'm finding myself in Flee, this may indicate that I'm feeling vulnerable or unsafe, and I perceive a need to protect myself. Can I voice this in a constructive, assertive manner? (3) When I'm finding myself stuck in Freeze, this may indicate that we have reached a dead end and that it is time to acknowledge and accept the situation as it is. From there, new options will likely emerge. (4) Once back in Flow, I keep assessing the situation on an ongoing basis and focus on the common goals: how can we use the dynamic tension between desired outcomes and current reality to move forward (Emerald 2009)?

Rather than analyzing the behavior of others, it is advisable to check that we are ourselves communicating from a Flow position. Otherwise, a student is likely to respond to a mismatch between the explicit, verbal message and a possibly contradictory, nonverbal (hidden) message. There are many reasons why someone may not be in Flow, and it is helpful to learn to understand ourselves: How do I recognize when I'm not in Flow? What may trigger me to move out of Flow? What position am I likely to go to? What strategies could help me move back into Flow? To move to a Flow position, I may remind myself what I like about a student and reflect on the student's particular strengths before focusing on their specific challenges. Note that if I find myself consistently unable to take an "I'm OK, you're OK" (Flow) position regarding a student, it may be time to actively end the supervisory relationship as it will likely not benefit the student.

It is often helpful to pay attention to body language and learn to recognize the signs of Fight, Flee, or Freeze (Fig. 2) in our students (Case Study 2); which of the three positions a student is in at any given moment is less important. The key is that they are not in Flow, so after checking that we're in Flow ourselves, we may then focus on helping the student find a way back to a Flow position, as constructive collaboration is only possible from there. The Functional Fluency model (Temple 2004, 2015) provides several options for communicating effectively from a Flow position. The model offers a behavioral map with a menu for choosing how to interact in a way that is mutually beneficial.

\section{Develop your Functional Fluency}

The Functional Fluency model (Temple 2004, 2015) is a model of human social behavior that can help us stay in Flow, or to find a way back there. The three basic categories of the model, which further divide into five elements, involve social responsibility, reality assessment, and self-actualization (Fig. 3). This makes the model relevant to both everyday and professional communication.

The "Accounting" element (Fig. 3, center) is an internal cognitive activity. The value-free way in which we use energy for Accounting is alert, aware, rational, and evaluative. Accounting is the term for the way in which we are constantly assessing the reality of our situation, though we are not necessarily aware of this. Being attuned to our inner and outer reality in the moment, we take a huge range of things into account to help us decide both what to do next and how to do it; whether to choose positive modes for responding rather than negative modes for reacting.

The "Being in Charge"' elements (Fig 3, top) refer to the two ways that we use energy on others' behalf (and on our own) when we are in a role that carries social responsibility and authority. The "Guiding and Directing" element can be "Structuring" (positive: inspiring, well-organized, firm) or "Dominating" (negative: bossy, fault-finding, punitive). The "Looking after People" element can be "Nurturing" (positive: accepting, understanding, compassionate) or "Marshmallowing" (negative: overindulgent, inconsistent, smothering), making four "Being in Charge" modes to choose from. 


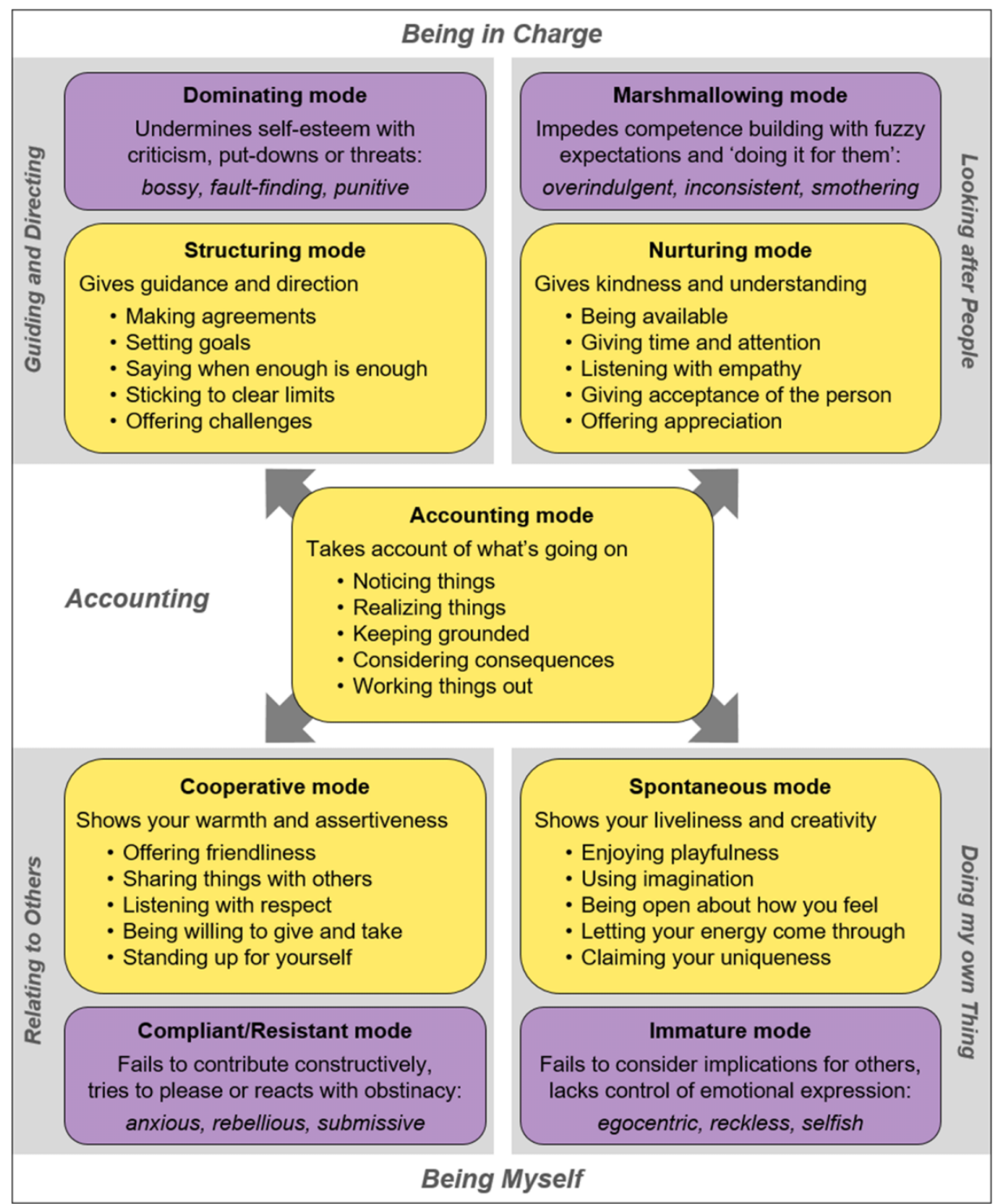

Fig. 3. All nine behavioral modes of the Functional Fluency model in action (based on Temple 2015). The five central boxes (gold color) illustrate the five positive modes, top and bottom boxes the corresponding negative modes (purple color). Arrows indicate how, from Accounting mode, we choose a blend of positive modes appropriate to the situation. Adapted from Temple (2015).

The "Being Myself" elements (Fig 3, bottom) refer to the two ways that we use energy on our own behalf when we are not in a role with social responsibility. The "Relating to Others" element can be "Cooperative" (positive: friendly, assertive, considerate) or "Compliant/Resistant" (negative: anxious, rebellious, submissive). The "Doing my own Thing" element can be "Spontaneous" (positive: creative, expressive, zestful) or "Immature" (negative: egocentric, reckless, selfish). There are thus four "Being Myself" modes to choose from. 
Functional Fluency is the term for healthy and positive ways of communicating using an appropriate blend of the five positive behavioral modes (Fig. 3) to respond effectively to different situations in real life, as illustrated with Case Study 2 (Box 2). On a bad day, and especially when we are not in Flow, we may slip into using the negative modes. That is when old habits can trip us up and we react rather than respond, which is often counter-productive. Many times, we are not aware that this reaction has more to do with the past than the present.

We can increase the effectiveness of Structuring and Nurturing by combining them in appropriate balance depending on the situation. As advisors, we may think that our main task is Structuring. However, if we do not balance Structuring with Nurturing, our behavior is likely to be perceived as Dominating, which undermines self-esteem. Likewise, Nurturing without appropriate Structuring can easily have a counter-productive effect of Marshmallowing, which impedes competence building (Fig. 3). Communicating with Cooperative and Spontaneous modes can help bridge the power gap and encourage students to take responsibility (Case Study 2). This may help them find a way back into a Flow position (Fig. 2).

In summary, it is not only what we say that matters, but how we say it. Authentic, congruent communication that encourages students and inspires them to learn, to be creative, and to succeed is only possible from a Flow position (Fig. 2). From there, using our Accounting facility we can choose to communicate with a blend of Structuring, Nurturing, Cooperative, and Spontaneous behaviors appropriate to the situation (Fig. 3). Dominating with criticism, threats, or warnings and a lack of empathy and encouragement may leave students feeling discouraged or persecuted, and this may keep them from focusing on their work. Marshmallowing with too much help and attention and a lack of clear expectations and inspiration lets students off the hook. This leaves them dependent and they may feel discouraged or helpless. As a result, Dominating and Marshmallowing may fuel conflict.

\section{Prevent and resolve conflicts}

We suggest that advisors strive to inspire students by helping them believe in their goals and in their abilities to work toward them and to address challenges as they arise. Advisors may actively encourage students to engage in negotiated agency, where students develop intentions and negotiate with others how to pursue them (Jazvac-Martek et al. 2011). When we lose the focus on intentions or desired outcomes, we are more likely to be drawn into unproductive dynamics that are difficult to stop because we are often unaware of them. In such situations, poor communication may fuel conflict. This section (1) highlights the "Drama Triangle" as a typical pattern of conflict in graduate advising and (2) considers "The Empowerment Dynamics" as an alternative model for effective collaboration between a graduate student and an advisor. Advisors or students can use Worksheet $\mathrm{F}$ (Supplementary Material) individually to refocus on their goals and engage in positive dynamics, as illustrated by Case Study 3 (Boxes 3 and 4).

\section{Recognize the drama triangle}

We may think that our conflicts are unique and that they result from personal incompatibilities. However, we have observed that many conflicts between advisors and graduate students share a common pattern, and are often triggered by typical situations that are part of the advising process. Recognizing the pattern is a big step toward stepping out of the unproductive and emotionally taxing dynamics known as the "Drama Triangle". The Drama Triangle (Karpman 1969, 2014; Fig. 4, bottom) is a model of the counter-productive interactions between people in conflict, where each person moves between the three roles of Victim, Persecutor, and Rescuer. 
Box 3. Case study 3.

Graduate advisor Dr. Delta is providing specific, constructive comments on graduate student Brown's manuscript. Delta has spent several hours reading and annotating the text-time that he had planned to spend working on his own publication. During the meeting, he walks Brown through the comments. While Brown is engaged initially, his attention is increasingly absorbed by emotions. By the end of the meeting, Brown walks a narrow line between snapping at the advisor and bursting into tears, and the best the student can do is to leave the room quickly. Alone in the office, Delta becomes increasingly irritated as he reflects on the lack of appreciation expressed by the student. Meanwhile, Brown seeks support from a fellow student, to whom he complains about the advisor.

What happened here? The advisor enters the Drama Triangle from the Rescuer position (Fig. 4, bottom). Delta feels obligated to help the student and puts the student's best interests before his own, discounting his own needs. While the advisor does a good job at identifying the shortcomings of Brown's manuscript so that the student can substantially improve his work, Delta forgets to balance the critical comments with positive feedback. Brown cannot absorb so much criticism, and as Delta goes on, the student increasingly perceives him as Persecutor. Brown picks up on the unspoken message "you are inadequate", thus taking the criticism personally. This undermines his self-esteem and the student feels Victimized. He is tempted to retaliate, moving to the Persecutor position, but he does not dare to do so until he is out of sight and among peers. Meanwhile, the advisor has moved to the Victim position: Delta feels ill-treated, without recognizing his own contribution to the situation. From there, he quickly moves to the Persecutor position and blames the student.

One way to step out of the Drama Triangle is to voice what we are observing about ourselves, while refraining from commenting about the other person (which might easily be perceived as Persecuting). For instance, atthe next meeting, Delta could voice the feeling of resentment at not being appreciated, or Brown could voice feeling discouraged, as there seemed to be nothing good about his work.

Dominating behaviors (Fig. 3) by the advisor invite the student into a Victim position, where the student perceives the advisor as Persecutor, whereas Marshmallowing behaviors often accompany Rescuing. Case Study 3 (Box 3) provides an example with the theme of "feedback gone wrong" that, based on our experience, may be observed daily in many departments. Typical characteristics of such Drama Triangle dynamics are the frequent switching of positions, which happens without the awareness of the participants, and high emotional intensity. Indeed, paying attention to our emotions, our bodily sensations and the other person's nonverbal communication may be the best ways to spot this type of conflict and bring it into awareness. It is not helpful to analyze the dynamics themselves, but rather to recognize them and to actively step out of the pattern, using positive modes of behavior (Fig. 3). Often, we will only be able to do so after the fact, when we have regained our composure.

\section{Focus on the goal}

Let's shift focus from the Drama Triangle as the problem to its proposed antidote, "Empowerment Dynamics" (Emerald 2009). Empowerment Dynamics provides a model for effective collaboration where we flexibly and consciously move between the roles of Creator, Challenger, and Coach (Fig. 4, top), as illustrated in the continuation of Case Study 3 (Box 4). This involves shifting from a 


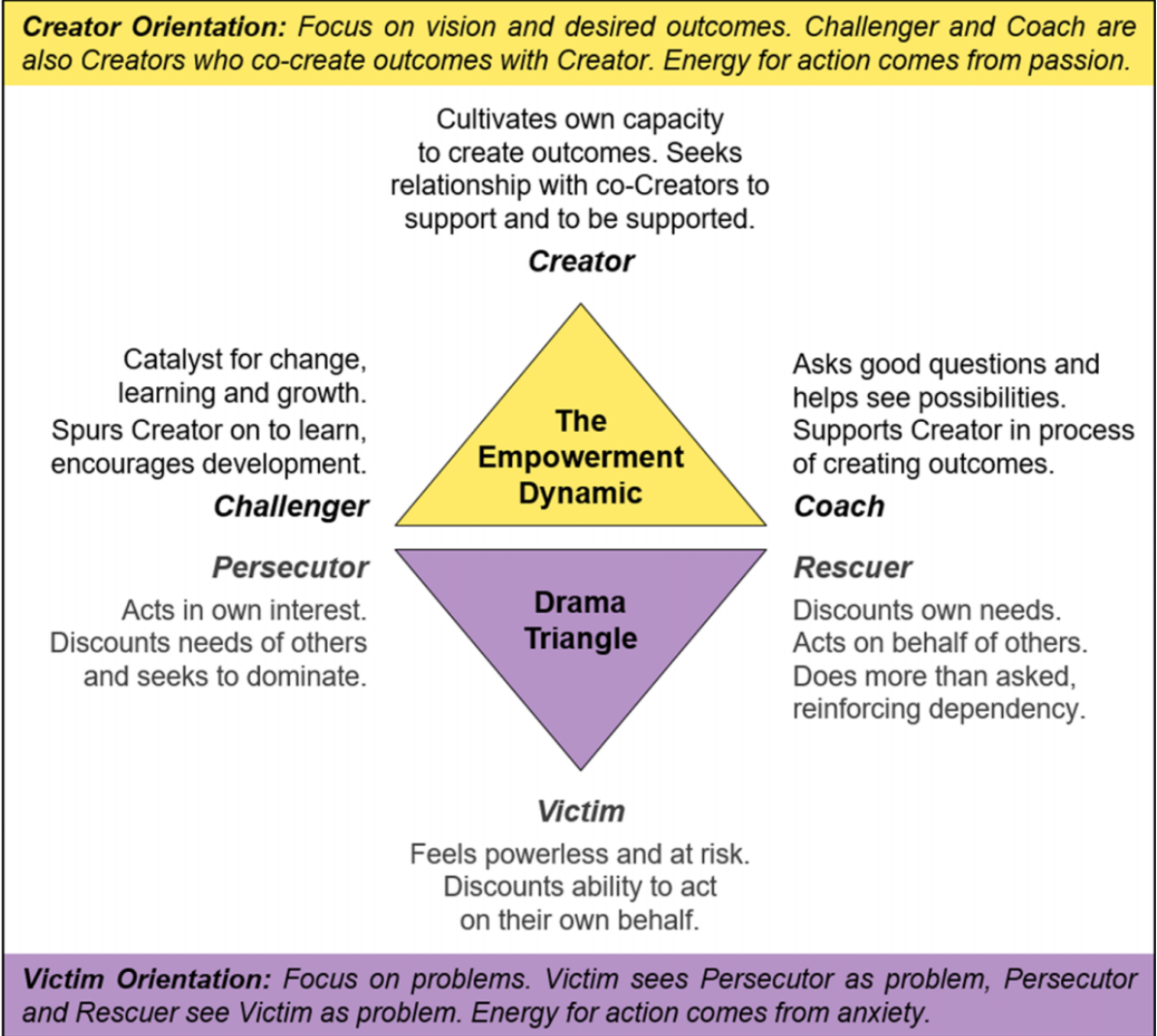

Fig. 4. Positions and main orientation of the "Drama Triangle" conflict model (bottom, purple color) and its antidote "The Empowerment Dynamic" (top, gold color). Adapted from Emerald (2009).

Victim orientation (focused on problems and based on anxiety) to a Creator orientation, where we focus on where we want to go and reconnect with our passion. The dynamic tension between our current reality assessment and the desired outcomes helps propel us forward to take the next small steps in the right direction (Emerald 2009; Worksheet F in the Supplementary Material).

Note that if a Discouraged Learner hits a roadblock, it is no good trying to focus on the vision before the student has identified the real problem and acknowledged how it affects them (see Worksheet D in the Supplementary Material). This requires active listening in a nonjudgmental environment where the student feels safe to open up.

It is helpful in this context to distinguish between our here-and-now fears and our fantasized, dire predictions of what may happen to us in the future. The fears are real, and naming them can help shift energy from anxiety toward passion (Thomson 1983). Fear, once it has been named, can signal to us what we need, such as more information to assess risk. When we are anxious we often construct predictions that are typically based on flawed assumptions. Hence, it is often helpful to acknowledge our fear, assess the reality of our predictions, and do some risk assessment using Accounting mode. Doing so means facing considerable uncertainty, as we cannot anticipate the future. However, by focusing on our vision and desired outcomes, we use our energy to move toward them, thus maximizing our ability to achieve our goals. 
Box 4. Case study 3 (continued).

How could the conflict have been averted in the first place? Initially, Delta feels torn between working on his own research and commenting on the student's manuscript. He acknowledges being concerned about Brown's progress, especially about a lack of independence of the student in reviewing his own writing. Delta also acknowledges that he is anxious to get published in time for his upcoming promotion. He decides to spend the most productive working hours on his own research with the goal of finishing a section, and to set aside an hour later in the day to read through Brown's manuscript with a focus on identifying the most important issues.

When meeting with Brown, Delta revisits Worksheet A (companion paper) and discusses with the student where he stands with his writing. Both agree that it is time for Brown to become more independent and review his own work (Cautious Performer). At this point, Delta perceives a sudden drop in Brown's spirits and asks: "I can sense some hesitation on your part. Are you concerned about anything?" The student nods quietly, and Delta asks whether he wants to explore this together. Brown agrees, and as the advisor listens patiently and offers a few prompting questions, Brown gradually explains that in school, he wasn't good at essay writing; he never understood how this should be done and it always made him feel stupid. Now Brown is afraid of failing as a graduate student because of a lack of writing skills, and as a result he finds it hard to actually sit down and work on the manuscript.

Delta acknowledges that such previous experiences can make it difficult to develop confidence, and points out that all graduate students need to learn how to write scientific articles. He offers to help Brown understand what he can do to improve the text. Delta commends Brown on working out a convincing storyline that can lead to a very strong thesis chapter. The next step would be to make sure that each sentence has a clear message that logically connects to the previous sentence, whereas minor issues of grammar and style could be fixed later. Delta points out an example where he perceived a break in the flow of the argument. He lets Brown identify what the problem is, and they discuss how the sentence could be improved. Then he shows Brown how he has marked up other instances where the sentence-level writing could be improved and asks whether the student is ready to give these a try. Brown confirms, and they agree that they will meet again the following week to go over the revisions.

What happened in this version? The advisor Delta starts by recognizing himself as a Creator (Fig. 4, top). He sorts out a conflict of interest between his roles as advisor and as researcher. He identifies the anxiety related to each role, and by focusing on each role separately, he manages to clarify what really matters right now and set realistic goals that he is motivated to achieve (see Worksheet B, companion paper).

Delta then considers the student Brown as a Creator and focuses on the bigger picture of the development of his writing skills instead of trying to fix the manuscript. Being attuned to Brown's nonverbal communication, Delta recognizes when to switch to a Coaching role. Delta uses mostly Cooperative and Nurturing behaviors (Fig. 3) to help Brown explore what is keeping him from making progress. Once Brown has acknowledged the problem and how it is affecting him, he relaxes, which the advisor takes as a sign that the student is now ready for specific comments, and Delta switches to a Challenger role. He helps Brown focus on the desired outcome of a strong thesis paper, understand the most important issues to be addressed to achieve this goal, develop the confidence that he can make the next small steps, and commit to a realistic deadline. 
The following description, reproduced with permission from an email written by a mentee, sums it up very well. Note the initial discount of the significance of the problem (Mellor and Schiff 1975), indicated by the word "unimportant" (quotation marks added below): "The meeting was helpful because initially I was feeling a little lost and was not able to concentrate on my work. When I shared this, I felt much relieved and it was great that you listened to these 'unimportant' things carefully. [...] Your motivational words, asking whether and how I can adapt to this situation, and our discussion on how I can move forward such as going to the conference and looking for a post-doc helped me to think about and look forward-because earlier I was not thinking about these things but was thinking about the tough time I am going through. As well, I knew that the revision of the manuscript would be a little tough but when I talked with you, I felt that it is going to be easy: I got inspired again”.

\section{Conclusion}

Effective collaboration between advisors and graduate students hinges upon their ability to communicate from a constructive position and to resolve conflict by acknowledging each other's perspective and focusing on their shared goals. We propose that miscommunication often happens out of a lack of understanding of the psychological aspects of human interactions, and advisors and students may get involved in unconstructive dynamics without being aware of them. We hope that the concepts and worksheets presented in this paper will enable advisors and students to increase their emotional literacy, choose effective ways of communication, and apply them to prevent and resolve conflict.

The type of open conversations illustrated in Case Studies 1 and 3 may not be common, due to lack of time or because they are not a priority. The key is to recognize when such a conversation is called for and then make it a priority and create the conditions to enable it. Helping a student get unstuck may save months in the student's project and eliminate some fruitless meetings along the way.

Worksheet G (Supplementary Material) shows how to pull the concepts and tools provided in this series together to analyze a current challenging situation and to identify steps toward enhancing the advisor-student working relationship. Alternatively, advisors and students may use Worksheet G (Supplementary Material) to bring to mind situations that have worked out well. They may thus use the past experience as an aid to imagining a desired future and to focus on planning how to make that positive future happen (Jackson and McKergow 2007; Kluger and Nir 2009).

Further research is required to elaborate the proposed links among concepts from different bodies of literature and to validate the applicability of the concepts for graduate advising. Limiting factors likely include the power differential, which may make it harder for students to open up about their challenges, and the transfer of concepts into practice with limited training. From a practical perspective it would be especially important to assess (1) whether learning about the concepts presented here promotes emotional literacy and communication skills, (2) whether having a common language and reference point as provided by this series helps advisors and graduate students communicate about emotional aspects of graduate advising, and (3) whether accounting for emotional aspects makes graduate advising more effective and enjoyable for advisors and graduate students.

\section{Acknowledgements}

All characters, names, and genders in the case studies are fictional. This work has been supported by the Robert Gillespie Academic Skills Centre, University of Toronto Mississauga, and by a Discovery grant of the National Sciences and Engineering Research Council (NSERC) of Canada to H. Wagner. We thank Cleo Boyd, Shekhar Biswas, Hans Jürgen Böhmer, Diego Carmona, Nick Collins, Marie-Josée Fortin, Benjamin Gilbert, Adam Hadley, Marc Johnson, Nusha Keyghobadi, 
Laura Taylor, Berend van den Broek, and Guojun Yang for comments on earlier versions of this manuscript. We thank Marie-Claire Shanahan and two anonymous reviewers for their valuable comments and suggestions.

\section{Author contributions}

Conceived and designed the study: HHW, ST, ID, RN. Contributed resources: HHW. Drafted or revised the manuscript: HHW, ST, ID, RN.

\section{Competing interests}

The authors have declared that no competing interests exist.

\section{Data accessibility statement}

All relevant data are within the paper and in the Supplementary Material.

\section{Supplementary material}

The following Supplementary Material is available with the article through the journal website at doi: 10.1139/facets-2015-0014.

Supplementary Material 1

\section{References}

Amundsen C, and McAlpine L. 2011. New academics as supervisors: a steep learning curve with challenges, tensions and pleasures. In Doctoral education: research-based strategies for doctoral students, supervisors and administrators. Edited by L McAlpine and C Amundsen. Springer, Amsterdam, the Netherlands. pp. 37-55.

Barrow G, and Newton T. 2016. Educational transactional analysis: an international guide to theory and practice. Routledge, Abingdon, UK. 316 p.

Berne E. 1961. Transactional analysis in psychotherapy. Grove Press, New York City, New York. 272 p.

Berne E. 1962. Classification of positions. Transactional Analysis Bulletin, 1: 23.

Berne E. 1964. Games people play. Grove Press, New York City, New York. 216 p.

Blanchard KH, Zigarmi P, and Zigarmi D. 1985. Leadership and the one minute manager: increasing effectiveness through situational leadership. Morrow, Scranton, Pennsylvania. 112 p.

Boud D, and Molloy E. 2013. Rethinking models of feedback for learning: the challenge of design. Assessment \& Evaluation in Higher Education, 38: 698-712. doi:10.1080/02602938.2012.691462.

Dimitrov N. 2009. Western guide to mentoring graduate students across cultures. The University of Western Ontario Teaching Support Centre, London, Ontario. 55 p.

Docheff D. 1990. The feedback sandwich. Journal of Physical Education, Recreation and Dance, 61: 17-18. doi:10.1080/07303084.1990.10604618.

Eckleberry-Hunt J, and Tucciarone J. 2011. The challenges and opportunities of teaching "Generation Y". Journal of Graduate Medical Education, 3: 458-461. doi:10.4300/jgme-03-04-15. 
Emerald D. 2009. The power of TED ${ }^{\star}\left({ }^{*}\right.$ The empowerment dynamic). 2nd edition. Polaris, Bainbridge Island, Washington. $176 \mathrm{p}$.

Ernst FH. 1971. The OK corral; the grid for get-on-with. Transactional Analysis Journal, 1: $231-240$.

Goleman D. 1996. Emotional intelligence: why it can matter more than IQ. Bloomsbury Publishing, London, UK. 368 p.

Hay J. 2009. Working it out at work: understanding attitudes and building relationships. 2nd edition. Sherwood Publishing, Broadoak End, UK. 224 p.

Heiller B, and Sills C. 2010. Life scripts: an existential perspective. In Life scripts: a transactional analysis of unconscious relational patterns. Edited by RG Erskine. Karnac Books, London, UK. pp. 239-267.

Hyland F, and Hyland K. 2001. Sugaring the pill-praise and criticism in written feedback. Journal of Second Language Writing, 10: 185-212. doi:10.1016/S1060-3743(01)00038-8.

Jackson PZ, and McKergow M. 2007. The solutions focus: making coaching and change simple. Nicholas Brealey International, London, UK and Boston, Massachusetts. 286 p.

Jazvac-Martek M, Chen S, and McAlpine L. 2011. Tracking doctoral student experience over time: cultivating agency in diverse spaces. In Doctoral education: research-based strategies for doctoral students, supervisors and administrators. Edited by L McAlpine and C Amundsen. Springer, Amsterdam. pp. 17-36.

Johnson DH. 2014. Reaching out: interpersonal effectiveness and self-actualization. 11th edition. Pearson Education, Boston, Massachusetts. 416 p.

Karpman SB. 1969. Fairy tales and script drama analysis. Transactional Analysis Journal, 7: 39-43.

Karpman SB. 2014. A game free life. Drama Triangle Publications, San Francisco, California. 299 p.

Kline N. 2009. More time to think. Fisher King Publishing, Pool-in-Wharfedale, UK. 304 p.

Kluger A, and Nir D. 2009. The feedforward interview. Human Resource Management Review, 20: 235-246. doi:10.1016/j.hrmr.2009.08.002.

Kolb DA. 2014. Experiential learning: experience as the source of learning and development. 2nd edition. Pearson Education, Upper Saddle River, New Jersey. 416 p.

Kruger J, and Dunning D. 1999. Unskilled and unaware of it: how difficulties in recognizing one's own incompetence lead to inflated self-assessments. Journal of Personality and Social Psychology, 77: 1121-1134. doi:10.1037/0022-3514.77.6.1121.

Macefield R, and Mellor K. 2006. Awareness and discounting: new tools for task/option-oriented settings. Transactional Analysis Journal, 36: 44-58. doi:10.1177/036215370603600107.

Mellor K, and Schiff E. 1975. Discounting. Transactional Analysis Journal, 5: 295-302.

Mezirow J. 1997. Transformative learning: theory to practice. New Directions for Adult and Continuing Education, 1997: 5-12. doi:10.1002/ace.7401. 
Mohr NM, Moreno-Walton L, Mills AM, Brunett PH, and Promes SB. 2011. Generational influences in academic emergency medicine: teaching and learning, mentoring, and technology (part I). Academic Emergency Medicine, 18: 190-199. doi:10.1111/j.1553-2712.2010.00985.x.

Molloy E, Borrell-Carrió F, and Epstein R. 2012. The impact of emotions in feedback. In Feedback in higher and professional education: understanding it and doing it well. Edited by D Boud and E Molloy. Routledge, London, UK. pp. 50-71.

Napper R, and Newton T. 2014. Tactics: transactional analysis concepts for all trainers, teachers and tutors and insight into collaborative learning strategies. 2nd edition. TA Resources, Ipswich, UK. $272 \mathrm{p}$.

O’Meara K, Knudsen K, and Jones J. 2013. The role of emotional competencies in faculty-doctoral student relationships. The Review of Higher Education, 36: 315-347. doi:10.1353/rhe.2013.0021.

Sadler DR. 1989. Formative assessment and the design of instructional systems. Instructional Science, 18: 119-144. doi:10.1007/BF00117714.

Steiner C. 1971. The stroke economy. Transactional Analysis Journal, 1: 9-15.

Steiner C. 2003. Emotional literacy: intelligence with a heart. Personhood Press, Fawnskin, California. 275 p.

Stevens-Long J, Schapiro SA, and McClintock C. 2012. Passionate scholars: transformative learning in doctoral education. Adult Education Quarterly, 62: 180-198. doi:10.1177/0741713611402046.

Temple S. 2004. Update on the functional fluency model in education. Transactional Analysis Journal, 34: 197-204.

Temple S. 2015. Celebrating functional fluency and its contribution to transactional analysis. Transactional Analysis Journal, 45: 10-22. doi:10.1177/0362153714568803.

Temple S. 2016. Becoming a teacher. In Educational transactional analysis. Edited by J Barrow and T Newton. Routledge, Abingdon, UK. pp. 47-60.

Thomson G. 1983. Fear, anger and sadness. Transactional Analysis Journal, 13: 20-24. 